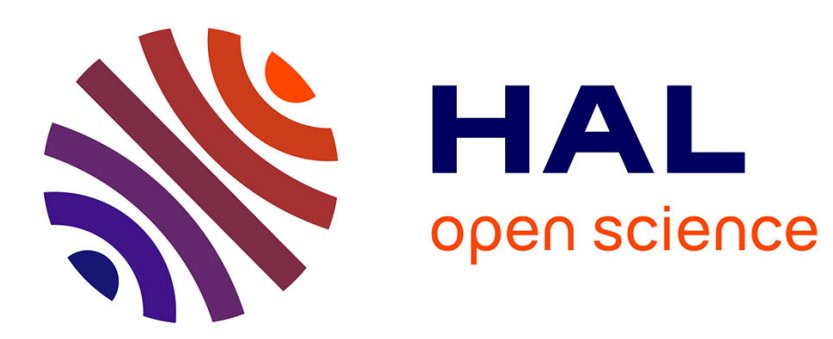

\title{
Kinematic regimes of convection at high Prandtl number in a shallow cavity
}

Jean-Marc Flesselles, Franck Pigeonneau

\section{To cite this version:}

Jean-Marc Flesselles, Franck Pigeonneau. Kinematic regimes of convection at high Prandtl number in a shallow cavity. Comptes Rendus Mécanique, 2004, 332 (10), pp.783-788. 10.1016/S16310721(04)00156-1 . hal-01442932

\section{HAL Id: hal-01442932 \\ https://hal.science/hal-01442932}

Submitted on 6 May 2017

HAL is a multi-disciplinary open access archive for the deposit and dissemination of scientific research documents, whether they are published or not. The documents may come from teaching and research institutions in France or abroad, or from public or private research centers.
L'archive ouverte pluridisciplinaire HAL, est destinée au dépôt et à la diffusion de documents scientifiques de niveau recherche, publiés ou non, émanant des établissements d'enseignement et de recherche français ou étrangers, des laboratoires publics ou privés. 


\title{
Kinematic regimes of convection at high Prandtl number in a shallow cavity.
}

\section{Régimes cinématiques de la convection à haut nombre de Prandtl dans une cavité allongée.}

\author{
Jean-Marc FLESSELLES ${ }^{\text {a }}$ Franck PIGEONNEAU ${ }^{\mathrm{a}}$

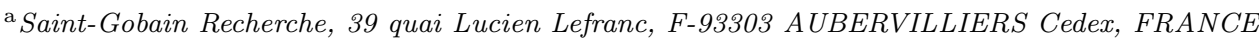

\begin{abstract}
We consider free convection in a horizontal shallow cavity with different end temperatures, filled with high Prandtl number fluid. From scaling analysis, we find two kinematic regimes resulting from the competition of heat transfer by conduction and by convection. Numerical simulations realized for a large range of Rayleigh number and aspect ratio confirm the phenomenological analysis and provide the threshold between the two regimes.

The conductive (resp. convective) regime occurs at $R a A^{2}$ smaller (resp. larger) than 443 , where $R a$ is the Rayleigh number and $A$ is the aspect ratio. In the convective regime, the characteristic velocity is independent of depth of the cavity.
\end{abstract}

To cite this article: J.-M. Flesselles, F. Pigeonneau, C. R. Mecanique xxx (2004).

\section{Résumé}

Nous traitons de la convection naturelle dans une cavité horizontale allongée différentiellement chauffée selon les parois verticales, emplie d'un fluide à grand nombre de Prandtl. L'analyse d'échelles fait apparaître deux régimes cinématiques résultant de la compétition entre transfert de la chaleur par conduction et par convection. Des simulations numériques faites dans une large gamme de nombre de Rayleigh et de facteur de forme confirment l'analyse phénoménologique.

Le régime conductif (resp. convectif) apparaît pour $R a A^{2}$ inférieur (resp. supérieur) à 443, où $R a$ est le nombre de Rayleigh et $A$ le facteur de forme. La loi d'échelle du régime convectif donne une vitesse caractéristique indépendante de la hauteur de la cavité.

Pour citer cet article: J.-M. Flesselles, F. Pigeonneau, C. R. Mecanique xxx (2004).

Key words: Fluid mechanics; natural convection; high Prandtl number

Mots-clés : Mécanique des fluides; convection naturelle; haut nombre de Prandtl 


\section{Version française abrégée}

Nous considérons une cavité allongée bidimensionnelle de hauteur $H$ et de longueur $L$ emplie d'un fluide incompressible de viscosité cinématique $\nu$, de diffusivité thermique $\kappa$ et de coefficient de dilatation volumique $\beta$ avec $\operatorname{Pr}=\nu / \kappa \gg 1$. Le champ de gravité est noté $g$. Les deux parois verticales sont placées respectivement à des températures fixes $T_{-}$et $T_{+}$. On note $\Delta T=T_{+}-T_{-}$et $A=H / L$.

Par une analyse phénoménologique réalisée dans le cadre de l'approximation de Boussinesq, nous montrons qu'il n'existe que deux régimes cinématiques selon la valeur de $R a A^{2}$. Cette quantité correspond au rapport du temps caractéristique de diffusion de la chaleur suivant la verticale au temps d'advection longitudinale.

Dans le régime conductif obtenu à faible valeur de $R a A^{2}$, la vitesse caractéristique est donnée par

$$
u_{0} \sim R a \frac{\kappa}{L} \text { avec } R a=\frac{g \beta \Delta T H^{3}}{\nu \kappa} .
$$

Dans le régime convectif, observé à grand $R a A^{2}$, la vitesse caractéristique a pour expression

$$
u_{0} \sim\left(R a A^{2}\right)^{-3 / 5} R a \frac{\kappa}{L} \sim(g \beta \Delta T / \nu)^{2 / 5} \kappa^{3 / 5} L^{1 / 5} .
$$

Cette analyse confirme celle précédemment faite par Boehrer [1] car nous retrouvons que le paramètre de contrôle est la quantité $R a A^{2}$. Par contre, nous concluons qu'il n'y a que deux régimes cinématiques alors qu'une analyse basée sur la thermique montrait trois régimes. Dans le régime convectif, la vitesse caractéristique ne dépend plus de la hauteur, et augmente avec la longueur de la cavité.

Nous avons réalisé plusieurs simulations numériques du problème considéré dans cette note en faisant varier le nombre de Rayleigh de 1 à $10^{9}$ et le facteur de forme de $1 / 2$ à $1 / 20$. La représentation de la composante longitudinale de la vitesse obtenue numériquement en fonction de $R_{a} A^{2}$ confirme les prédictions théoriques. La transition entre les deux régimes est assez franche. Elle est observée pour $R a A^{2} \simeq 443$.

\section{Introduction}

Despite the amount of work devoted to natural convection, the subject is not yet exhausted because of the variety of situations of interest, the number of possible control parameters and the subtlety of the effects at play. The purpose of this note is to determine the different kinematic regimes that occur in a two-dimensional cavity with end walls kept at fixed temperature and filled with a high Prandtl number fluid.

The side-heated cavity is an academic model for many realistic situations of natural or technological flows. It has first been introduced by Batchelor [2] to study air circulation in buildings. In this case, the geometry - a tall and thin cavity - is characterized by a large aspect ratio $A$ and the fluid, namely air, is characterized by a Prandtl number of order 1 . The situation of a shallow cavity (with a small aspect ratio) also received much attention since it applies to a large number of geophysical flows, like estuaries or waste heat disposal. Studies concentrated on low Prandtl number fluids like air $(\operatorname{Pr}=0.7)$ or water $(\operatorname{Pr}=7)$ which are most commonly encountered, but a few authors have also studied high Prandtl number flows.

Boehrer published [1] a comprehensive analysis of all available experimental data as well as possible theoretical scalings for the flow of a fluid in a two-dimensional shallow cavity with end heated walls,

Email addresses: jean-marc.flesselles@saint-gobain.com (Jean-Marc FLESSELLES), franck.pigeonneau@saint-gobain.com (Franck PIGEONNEAU). 
within the Boussinesq approximation. He deplored that no clear understanding of the various regimes that may occur in such an apparently simple flow would yet emerge and suggested a global picture of the convection regimes as well as the relevant control parameters.

According to him, his analysis applies to long cavities $(0<A<0.25)$, provided the Rayleigh number is not excessively high $\left(R a<A^{-12}\right)$, and filled with any fluid such that the Prandtl number is larger than unity. His main results are the following : the relevant control parameter is $R a A^{2}$, where $R a$ is the Rayleigh number ; there exist three regimes, called conductive regime, transition regime and convective regime, the boundaries of which are at $R a A^{2} \simeq 10^{2}$ and $R a A^{2} \simeq 10^{4}$. He also provides estimates for the temperature gradient in the core of the cavity.

Boehrer's analysis is based on a comparison of published data, together with a physical analysis of the different scaling, and a systematic re-plotting of all data according to the different hypothesis. However, Boehrer emphasis is essentially put on the temperature gradient within the core of the cavity.

Following Boehrer, we have reconsidered the case of high Prandtl number fluids. Our analysis is based on a physical analysis of the scaling laws and extensive computational fluid dynamics simulations. We deduce that, from a kinematic point of view, two regimes only exist. We provide the threshold between them and the laws for the velocity scale in each regime.

\section{Formulation}

We consider a two-dimensional rectangular shallow cavity of height $H$ and length $L$ filled with an incompressible fluid of constant kinematic viscosity $\nu$ and constant heat diffusivity $\kappa$. The heat expansion coefficient of the fluid is $\beta$. The cavity is in the gravity field $g$. One vertical side of the cavity is kept at a hot fixed temperature $T_{+}$and the opposite side is kept at a cold temperature $T_{-}$. The temperature difference is $\Delta T=T_{+}-T_{-}$. Top and bottom sides are adiabatic. The fluid velocity vanishes on all sides. The Boussinesq approximation is assumed.

The continuity equation writes

$$
\frac{u_{0}}{L} \frac{\partial u}{\partial x}+\frac{v_{0}}{H} \frac{\partial v}{\partial y}=0
$$

where $x=\bar{x} / L, y=\bar{y} / H, u=\bar{u} / u_{0}, v=\bar{v} / v_{0}$ and overlines indicate dimensional variables. The scaling variables $u_{0}, v_{0}$ for horizontal and vertical velocity scales are still unknown. Eq. (3) sets the relation between them:

$$
v_{0} \sim(H / L) u_{0}
$$

Since the aspect ratio $A=H / L$ is very small, $v_{0}$ is much smaller than $u_{0}$ : the flow is parallel (except near the lateral walls). With the use of eq. (4), the equations of motion are:

$$
\begin{aligned}
S t \frac{\partial u}{\partial t}+u \frac{\partial u}{\partial x}+v \frac{\partial u}{\partial y} & =-\frac{\delta P}{\rho_{0} u_{0}^{2}} \frac{\partial P^{\prime}}{\partial x}+\frac{\nu}{u_{0} L A^{2}}\left[A^{2} \frac{\partial^{2} u}{\partial x^{2}}+\frac{\partial^{2} u}{\partial y^{2}}\right] \\
A^{2}\left(S t \frac{\partial v}{\partial t}+u \frac{\partial v}{\partial x}+v \frac{\partial v}{\partial y}\right) & =-\frac{\delta P}{\rho_{0} u_{0}^{2}} \frac{\partial P^{\prime}}{\partial y}+\frac{\nu}{u_{0} L}\left[A^{2} \frac{\partial^{2} v}{\partial x^{2}}+\frac{\partial^{2} v}{\partial y^{2}}\right]+\frac{\beta \Delta T g H}{u_{0}^{2}} \theta \\
S t \frac{\partial \theta}{\partial t}+u \frac{\partial \theta}{\partial x}+v \frac{\partial \theta}{\partial y} & =\frac{\kappa}{u_{0} L A^{2}}\left[A^{2} \frac{\partial^{2} \theta}{\partial x^{2}}+\frac{\partial^{2} \theta}{\partial y^{2}}\right]
\end{aligned}
$$

in which the Strouhal number $S t$ is defined by $S t=L /\left(u_{0} t_{0}\right)$. In eq. (5-7), new unknown scaling variables for time, density and pressure have been introduced with the corresponding nondimensional variables: $t=\bar{t} / t_{0}, \rho=\bar{\rho} / \rho_{0}, P=\bar{P} / \delta P$. Nondimensional temperature is $\theta=\left(T-T_{-}\right) /\left(T_{+}-T_{-}\right)$. 
The scaling variables correspond to the maximum values attained within the domain where the scaling applies: it is the central region where the flow is parallel. In the next section, we determine these variables by a phenomenological analysis [3]. It relies on the least degeneracy principle, according to which the largest possible number of terms should be kept (see $[4,5])$.

\section{Phenomenological analysis}

From eq. (7), one deduces that

$$
\kappa /\left(u_{0} L A^{2}\right) \sim \max (S t, 1)
$$

We first consider the case where $S t \gg 1$, which means that the typical horizontal advection distance is much smaller than the length of the cavity. In this case, eq. (8) yields the time scale:

$$
t_{0} \sim H^{2} / \kappa
$$

It is a characteristic thermal diffusion time over height $H$. When inserted into eq. (5), with the assumption of large Prandtl number $(\operatorname{Pr} \gg 1)$, this yields a relation between pressure and velocity scales:

$$
\delta P /\left(\rho_{0} u_{0}^{2}\right) \sim \nu /\left(u_{0} L A^{2}\right) .
$$

This, with eq. (6), sets the $u_{0}$ velocity as proportional to the $H$ based Rayleigh number:

$$
u_{0} \sim R a \frac{\kappa}{L} \quad \text { with } \quad R a=\frac{g \beta \Delta T H^{3}}{\nu \kappa} .
$$

This equation may be written in a nondimensional way by introducing the Péclet number:

$$
P e \sim R a \text { with } P e=\frac{u_{0} L}{\kappa} .
$$

It is easily checked that the $S t \gg 1$ condition also writes $R a A^{2} \ll 1$.

The Strouhal number may also be seen as the ratio of the horizontal advection time scale to the vertical thermal diffusion time scale. Hence we call this low Rayleigh number regime the conductive regime since the motion is controlled by the (long) thermal time scale. A temperature perturbation has time to equilibrate vertically because of thermal diffusion before being advected along the length of the cavity: isotherms are essentially vertical, which corresponds to a conductive solution.

On the other hand, if the Strouhal number becomes small enough, hence at large Rayleigh number, a thermal perturbation will travel along the cavity. This means that a horizontal boundary layer of thickness $\delta$ has appeared, within which the fluid moves to the vertical walls. This thickness is such that the Strouhal number associated to it is equal to unity:

$$
\kappa L /\left(\delta^{2} u_{0}\right) \sim 1
$$

Vertical length scales should be rescaled with $\delta$ instead of $H$. A similar analysis to the previous one may be performed. One finds that the Péclet number is no more equal to the Rayleigh number:

$$
P e \sim R a(\delta / H)^{3} \text {. }
$$

The size of the boundary layer is found by inserting eq. (14) in eq. (13). Finally one gets the final expression of the (nondimensional) velocity in the convective regime:

$$
P e \sim R a\left(R a A^{2}\right)^{-3 / 5} .
$$




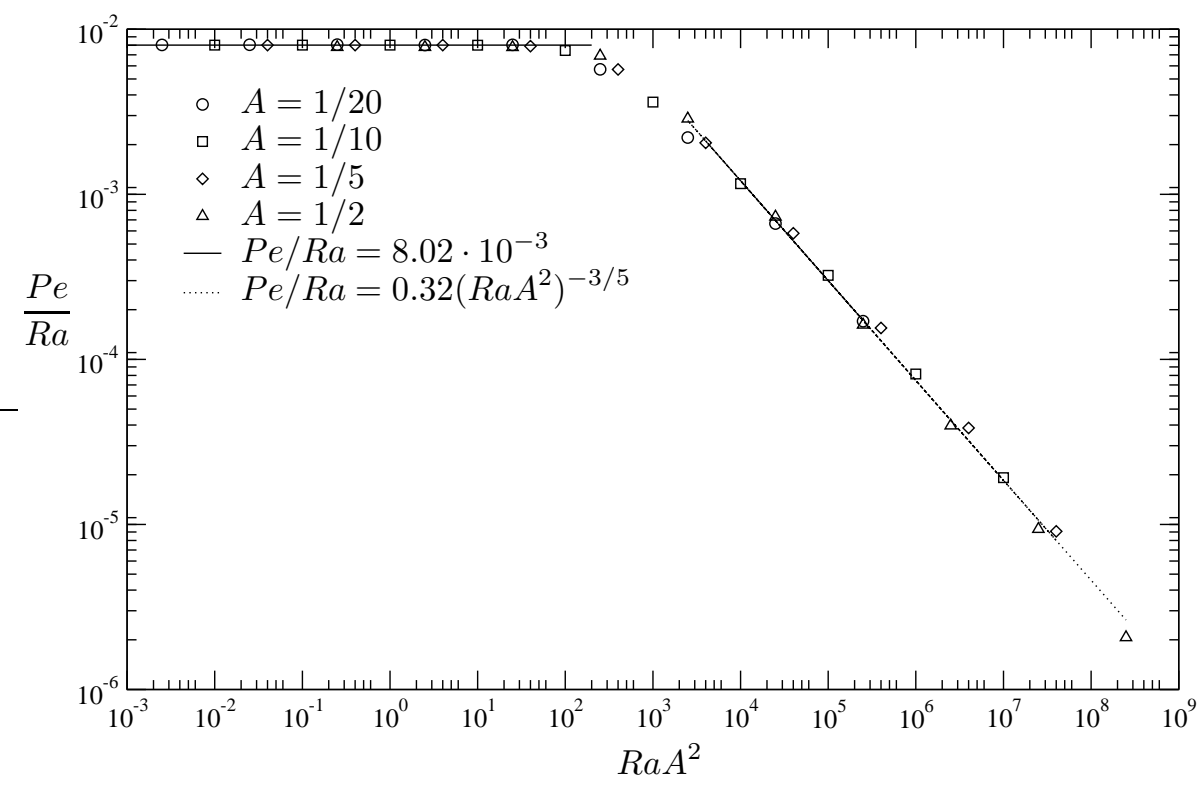

Figure 1. Nondimensional maximum value of the $x$-velocity component in shallow cavities of various aspect ratios $A$ vs. $R a A^{2}$ for a high-Prandtl number fluid.

Figure 1. Valeur maximale de la composante $x$ de la vitesse adimensionnée dans des cavités de différents facteurs de forme $A$ en fonction de $R a A^{2}$ pour un fluide de haut nombre de Prandtl.

The previous analysis sets on firm grounds the analysis and hypothesis of Boehrer: we recover the role of the quantity $R a A^{2}$ as the control parameter and we derive rigorously the relevance of the conductively controlled boundary layer, based on the advection time scale. In addition, we show that there exists only two kinematic convection regimes, whereas the current understanding focuses on the thermal field, and leads to a three regime classification.

\section{Comparison to numerical data}

In order to check the theoretical predictions (12) and (15), we have performed extensive numerical simulations of the problem expressed in the appropriate nondimensional variables. In a permanent state, the equations of motion write:

$$
\begin{aligned}
\frac{\partial u}{\partial x}+\frac{\partial v}{\partial y} & =0, \\
u \frac{\partial u}{\partial x}+v \frac{\partial u}{\partial y} & =-\frac{\partial P^{\prime}}{\partial x}+\frac{P r}{R a A} \nabla^{2} u, \\
u \frac{\partial v}{\partial x}+v \frac{\partial v}{\partial y} & =-\frac{\partial P^{\prime}}{\partial y}+\frac{P r}{R a A} \nabla^{2} v+\frac{P r}{R a A^{2}} \theta, \\
u \frac{\partial \theta}{\partial x}+v \frac{\partial \theta}{\partial y} & =\frac{1}{R a A} \nabla^{2} \theta,
\end{aligned}
$$

where velocities are normalized by $R a \kappa / L$, and lengths by $H$. Eq. (16-19) are solved with a commercial CFD code in a rectangular box of height 1 , and length $1 / A$, filled with a fluid of viscosity $\operatorname{Pr} / \operatorname{Ra} A$, of 
thermal conductivity $1 / R a A$, and of thermal expansion coefficient $\operatorname{Pr} / \operatorname{Ra} A^{2}$.

About 40 cases have been run, where the aspect ratio $A$ was varied between $1 / 20$ and $1 / 2$ and the Rayleigh number $R a$ was varied in the range 1 to $10^{9}$. The Prandtl number was fixed, and equal to 1000. With the considered nondimensional variables, the maximum value of the $x$ component of the velocity is equal to $P e / R a$. Its value is reported a function of $R a A^{2}$ on Fig. 1. In accordance with the phenomenological analysis $P e / R a$ is constant at low $R a A^{2}$, i.e. in the conductive regime. This constant value is easily calculated in the $R a \rightarrow 0$ limit. It is equal to $1 / 72 \sqrt{3} \simeq 8.02 \cdot 10^{-3}$ [6]. At high $R a A^{2}$, i.e. in the convective regime, $\mathrm{Pe} / \mathrm{Ra}=0.32\left(R a A^{2}\right)^{-3 / 5}$, where the proportionality constant comes from a fit. The intersection between the two scalings provides the regimes boundary. It is rather sharp and occurs at $R a A^{2} \simeq 443$.

\section{Conclusion}

The numerical data are in perfect agreement with our phenomenological analysis. These results both confirm and extend Boehrer's analysis: the relevant control parameter for natural convection of a highPrandtl number fluid in a shallow box is indeed $R a A^{2}$, which is the ratio of the heat diffusion time scale to the convection time scale. There are only two kinematic regimes, and the only condition lies on $R a A^{2}$, provided $\operatorname{Pr}>1$.

In the convective regime, that occurs when $R a A^{2} \gtrsim 443$, a boundary layer develops. As this new length scale sets in the problem, the velocity scale changes. When expressed in dimensional quantities, the velocity coming from eq. (15) writes:

$$
u_{\max }=0.32\left(\frac{g \beta \Delta T}{\nu}\right)^{2 / 5} \kappa^{3 / 5} L^{1 / 5}
$$

Hence, contrary to the intuitive understanding, the velocity does not depend on depth any more and increases with the length of the cavity, in full agreement with theoretical prediction and numerical results.

\section{Acknowledgements}

We thank X. Chavanne for numerous and fruitful discussions.

\section{References}

[1] B. Boehrer, Convection in a long cavity with differentially heated end walls, Int. J. Heat Mass Transfer 40 (1997) 4105-4114.

[2] G. K. Batchelor, Heat transfer by free convection across a closed cavity between vertical boundaries at different temperatures, Quart. of Appl. Math. 12 (1954) 209-233.

[3] A. Bejan, Convection heat transfer, John Wiley \& Sons, New York, 1995.

[4] P. Germain, Méthodes asymptotiques en mécanique des fluides, in: Fluid dynamics, Gordon and Breach, London, 1977, pp. $1-147$.

[5] R. K. Zeytounian, Modélisation asymptotique en mécanique des fluides newtoniens, Springer-Verlag, 1994.

[6] D. E. Cormack, L. G. Leal, J. Imberger, Natural convection in a shallow cavity differentially heated end walls. Part 1. Asymptotic theory, J. Fluid Mech. 65 (1974) 209-229. 